\title{
Development and validation of psychological status questionnaire for parents of infantile hemangiomas
}

\author{
Wei Peng ${ }^{1,2,3 \#}$, Haijin Liu ${ }^{1,2,3 \#}$, Jincai Chen ${ }^{4 \#}$, Yanan Zheng ${ }^{5}$, Xianyun $\mathrm{Xu}^{6}$, Hong Tang ${ }^{5}$, Qian Liu ${ }^{1,7,8}$ \\ ${ }^{1}$ Department of Graduate School, China Medical University, Shenyang, China; ${ }^{2}$ Department of Pediatric Surgery, The First Affiliated Hospital of \\ Gannan Medical University, Ganzhou, China; ${ }^{3}$ Department of Clinical Research Center of Vascular Abnormalities of Jiangxi Province, Ganzhou, \\ China; ${ }^{4}$ Department of Orthopedics, The First Affiliated Hospital of Gannan Medical University, Ganzhou, China; ${ }^{5}$ Department of Medical \\ Psychology, Gannan Medical University, Ganzhou, China; ${ }^{6}$ Department of Basic Medical Science, Gannan Medical University, Ganzhou, China; \\ ${ }^{7}$ Department of Graduate School, Jiangxi University of Chinese Medicine, Nanchang, China; Jiangxi Provincial Key Laboratory of Traditional \\ Chinese Medicine Prevention and Treatment of Hemangioma, Jiangxi University of Chinese Medicine, Nanchang, China \\ Contributions: (I) Conception and design: H Tang, Q Liu; (II) Administrative support: Y Zheng, X Xu; (III) Provision of study materials or patients: \\ H Liu; (IV) Collection and assembly of data: W Peng, H Liu; (V) Data analysis and interpretation: W Peng, J Chen; (VI) Manuscript writing: All \\ authors; (VII) Final approval of manuscript: All authors. \\ "These authors contributed equally to this work and should be considered as co-first authors. \\ Correspondence to: Qian Liu. Graduate School, China Medical University, 77 Puhe Road, Shenyang North New Area, Shenyang 110122, China. \\ Email: liuqiangmu2017@126.com.
}

Background: Infantile hemangioma (IH) is the most frequent benign tumor of infancy which impacts the psychological status of parents of affected children. Parental psychological status has a significant effect on the therapeutic effect and long-term prognosis of IH children. However, no standard questionnaires had been established previously to assess the psychological status of Chinese parents of children with IH.

Methods: This study prospectively developed and validated a psychological status instrument for the assessment of parents of patients with $\mathrm{IH}$ and to identify clinical features with effects on the psychological status. A total of 350 parents completed the 35-item Psychologic Status Questionnaire for parents of Infantile Hemangiomas (IH-PSQ) and provided demographic information. The IH-PSQ was refined via item analysis, validity analysis (including exploratory factor analysis and criterion-related validity) and reliability analysis (including internal consistency reliability, split half reliability, and test-retest reliability).

Results: The dimensionality of the items was evaluated using factor analysis, with results suggesting 5 factors: anxiety, depression, psychological imbalance, disease shame, and disease fear. The final instrument consists of 4 scales with a total of 23 items. Construct validity was demonstrated and IH-PSQ showed good internal coherence (Cronbach's $\alpha$ : 0.957), good split half reliability (0.971), and good test-retest reliability (correlation coefficient: 0.967). The correlation coefficient between the Self-Rating Anxiety Scale (SAS) and Self-rating Depression Scale (SDS) of children with IH was 0.874 and 0.754 , respectively. Multiple linear regression analysis found that some characteristics will affect the score of IH-PSQ.

Conclusions: The IH-PSQ contains 5 dimensions and 23 entries, and with good reliability and validity, can objectively and effectively evaluate the psychological status of $\mathrm{IH}$ parents. Certain clinical characteristics of IH families, including parents' own factors (including their monthly income and cultural level) and disease-related factors of affected children (including the duration of illness, tumor size, with or without complications, single or multiple, whether being treated or not), were associated with a greater impact on IH-PSQ.

Keywords: Infantile hemangioma (IH); questionnaire; psychological status; validation; impact

^ ORCID: 0000-0001-7682-2869. 
Submitted Oct 20, 2021. Accepted for publication Dec 16, 2021.

doi: $10.21037 / \mathrm{tp}-21-554$

View this article at: https://dx.doi.org/10.21037/tp-21-554

\section{Introduction}

Infantile hemangioma (IH) is one of the most common benign tumors in infants, the incidence of which can reach $4-5 \%$ (1). It is mostly located on the face and neck $(2,3)$, and has a specific natural course, including a stage of hyperplasia, regression, and extinction. Some IHs are selflimiting and require no specific treatment (4). However, professor Jinzhe Zhang, one of the founders of China's first pediatric surgery department (5), repeatedly emphasized that the management of $\mathrm{IH}$ was prone to overtreatment, as most of the treatment rendered did not take the natural course of the disease into consideration (6). Many authors have labeled the overtreatment of IH as unnecessary (7-9). However, these authors have tended to place more focus on the diagnosis and treatment of the disease and ignore the influence of parental psychological factors.

As we know, overtreatment is a medical behavior or a medical process, which is caused by a variety of causes exceeding the actual need for diagnosis and treatment of the disease (10). As to the cause of overtreatment, besides the current medical process and ethical aspects, one of the most important contributing factors is the patient expectations or pressure/request, which cannot be ignored during the course of treatment $(11,12)$. At the proliferative phase, IH typically grows rapidly, with the classical clinical manifestations of flushed skin on the face and around the head and neck. This has an enormous effect on the child's appearance, even causing obvious facial deformity $(13,14)$. The physical appearance of the child has a psychological impact on both children and parents $(15,16)$. These complicated psychological states disrupt the clear communication between doctors and patients, thereby undermining the parents or caregiver's understanding of $\mathrm{IH}$ and its treatment (17). It is therefore paramount to clearly understand the parents or caregiver's psychological state in order to provide proper counseling for appropriate and effective management (18). Unfortunately, there were previously no standardized questionnaires about the psychological status for Chinese parents with IH children.

To address this, the aim of current study was to design and validate a Psychological Status Questionnaire for Infantile Hemangiomas' parents (IH-PSQ). We hypothesized that IH impacts the affected the parent's emotional and social functioning. This paper describes the development and validation of IH-PSQ instrument for measuring the psychological status of IHs' parents during this early critical period.

We present the following article in accordance with the MDAR reporting checklist (available at https://dx.doi. org/10.21037/tp-21-554).

\section{Methods}

The questionnaire was developed according to standard questionnaire development guidelines and methodologies (19) according to the following steps: questionnaire creation, questionnaire validation, and analysis of influencing factors. A multidisciplinary team, composed of health care professionals such as $3 \mathrm{IH}$ experts, 3 psychologists, and $2 \mathrm{IH}$ nursing experts, collaborated with the $\mathrm{IH}$ patients and their families.

\section{Statistical analysis}

The data collected were entered and analyzed using SPSS 20.0. Statistical analyses included descriptive statistics, factor analyses, reliability analyses, product-moment correlations, independent-sample $t$-tests, One-way ANOVA and regression analyses.

\section{Questionnaire creation}

During the conceptual phase, a series interview was conducted with clinicians, patient-reported outcome experts, and IH parents to collect parents' opinions and complaints as the initial interview questions. Semistructured individual interviews of $10 \mathrm{IH}$ children's parents were then conducted. Participants were asked questions about psychological status for the disease. Answers were transcribed and a content analysis of the responses was carried out according to published methodology, in order to build an initial wording report. Based on this initial wording report, the working group drew up a list of items that were reformulated as simple, comprehensible questions. They evaluated the grammar, wording, and 
scaling of each item.

\section{Questionnaire validation}

During this phase, the initial questionnaire and the correlated demographic and clinical features questionnaire were administered to a random sample of parents of $\mathrm{IH}$ patients $(n=350)$. After reading the informed consent form, the parents completed the questionnaire survey on the spot while waiting at the Clinical Research Center of Vascular Abnormalities in Jiangxi Province, China.

Then, the item analysis of the questionnaire was determined using extreme value comparisons (decision values), entries and total score correlation (including entries and total score correlation, correction entries, and total score), and homogeneity test (including the alpha value after deletion, commonality, and factor load). The validity evaluation of the initial IH-PSQ was mainly based on two aspects: exploratory factor analysis and criterion-related validity. A total of 50 parents of IH children were randomly selected to complete an SAS (Self-rating Anxiety Scale) and SDS (Self-rating Depression Scale) at the same time. Pearson correlation analysis was conducted between the initial IH-PSQ and the scores of SAS and SDS to verify the validity of the questionnaire; The reliability analysis of the initial IH-PSQ was mainly based on three aspects: including internal consistency reliability, split half reliability, and test-retest reliability. Complete data was available for 50 (randomly selected) participants tested at the 2-week interval, to verity the test-retest reliability.

\section{Analysis of influencing factors}

In order to exclude the possible interaction between factors, this study used multiple linear regression to analyze the influencing factors of the questionnaire. According to the character of the data, this study set the working conditions of the parents, home address, duration of illness, and the main caregivers as the dummy variables; the educational level of the parents, number of children, monthly income of the family, whether the child had been treated, single or multiple hemangioma, tumor size, and whether there were complications as independent variables, and the score of IH-PSQ as the dependent variable. Backward regression analysis was used to screen the influencing factors of the score of IH-PSQ.

All procedures performed in this study involving human participants were approved by the Ethics Committee of
The First Affiliated Hospital of Gannan Medical University (No. LLSC-2021062503) and were in accordance with the Declaration of Helsinki (as revised in 2013). All participants voluntarily participated in the study and signed a written informed consent before taking part.

\section{Results}

\section{Questionnaire creation}

According to the results of the semi-structured phenomenological interview with the parents of $\mathrm{IH}$ children, feelings mentioned more than four times were selected as the initial item (total 35 items), which formed the item pool.

A total of 10 parents of children with $\mathrm{IH}$ read the items severally, and proposed amendments on the existence of ambiguity, inaccurate expression, and unrealistic entry. The multidisciplinary team evaluated and corrected the objectivity, accuracy, comprehensiveness, and the form of the questionnaire entries. The initial questionnaire was formed according to the results of this evaluation (Table 1). The answer option was based on the LIKERT 5-level system for quantification as follows: "never/not applicable" means 0 point, "rarely" means 1 point, "sometimes" means 2 points, "often" means 3 points, "very often" means 4 points, and "constantly" means 5 points. To prevent confusion with any changes in perception due to symptoms related to comorbidities, the majority of questions included the wording "After your child got IH".

\section{Questionnaire validation}

\section{Correlated demographic and clinical features}

A total of 350 initial questionnaires were distributed, and the recovery rate was $100 \%$. We excluded 27 questionnaires on account of the questionnaire being incomplete, leaving a total of 323 (92.29\%) effective questionnaires.

Table 2 and Table 3 show the demographic data of the 323 participants and their children, which were collected from their parents through self-reported questionnaires.

\section{Item analysis}

The item analysis of the entire initial questionnaire is shown in the Table 4, and the criteria for each line are at the bottom of the table. Even if only one rule was violated, the item was deleted. The results showed that item 1 , item 4 , item 11 , item 21 , item 26 , item 29 , item 31 , and item 35 did 
Table 1 The initial IH-PSQ 35-items (score from 0 to 5)

1. After my child got $\mathrm{IH}$, the time of taking children out to play was less than before

2. After my child got IH, I was depressed and not in a high mood

3. After my child got IH, I was more nervous and anxious than usual

4. After my child got $\mathrm{IH}$, I was worried about the change of condition

5. After my child got IH, I felt God was unfair to me and my child

6.After my child got $\mathrm{IH}, \mathrm{I}$ felt that my children needed more love than other children

7. After my child got IH, I slept worse than before

8. After my child got $\mathrm{IH}$, my digestion deteriorated

9. After my child got IH, I was afraid to look at the affected part of the child

10. After my child got IH, I would think of my own child and feel uncomfortable when I saw other people's healthy children

11. After my child got IH, I didn't want to talk to others about my child

12. After my child got $\mathrm{IH}$, things were not as interesting as before

13. After my child got $\mathrm{IH}, \mathrm{I}$ was prone to nightmares

14. After my child got IH, I felt nervous every time we had a doctor's appointment or regular check-up

15. After my child got IH, I attributed the cause of illness to myself

16. After my child got $\mathrm{IH}$, life was not as comfortable as before

17. After my child got IH, I was more likely to be angry than before

18. After my child got IH, I was upset about many things

19. After my child got IH, I worried that our future children would also experience this disease

20. After my child got IH, I felt that this family was not good enough for my child

21. After my child got IH, I felt that others would be biased because of $\mathrm{IH}$

22. After my child got $\mathrm{IH}$, I was more likely to feel tired

23. After my child got IH, I quarreled with the people around me more than before

24. After my child got IH, I was worried that the treatment would affect their growth and development

25. After my child got $\mathrm{IH}, \mathrm{I}$ felt the $\mathrm{IH}$ of other children recovered better than mine

26. After my child got $\mathrm{IH}, \mathrm{I}$ was afraid to expose the affected areas

27. After my child got $\mathrm{IH}$, I did not want any entertainment

28. After my child got $\mathrm{IH}$, I felt unhappy

29. After my child got $\mathrm{IH}$, I was worried that $\mathrm{IH}$ could not be cured

30. After my child got $\mathrm{IH}, \mathrm{I}$ thought everyone made mistakes

31. After my child got IH, I felt that my child was not as cute as before

32. After my child got $\mathrm{IH}$, my living and working conditions were not as good

33. After my child got $\mathrm{IH}$, it was difficult for me to calm down and think

34. After my child got IH, I sought medical advice everywhere

35. After my child got IH, I felt doctors did not care enough about my child

Tips: with $0=$ never/not applicable, $1=$ rarely, $2=$ sometimes, $3=$ often, $4=$ very often, $5=$ constantly. IH-PSQ: Psychologic Status Questionnaire for parents of Infantile Hemangiomas; IH, infantile hemangioma. 
Table 2 Demographic data of the IHs' parents ( $n=323)$

\begin{tabular}{|c|c|c|}
\hline Characteristic & Number & Proportion (\%) \\
\hline \multicolumn{3}{|l|}{ Parent } \\
\hline Father & 100 & 31.0 \\
\hline Mother & 223 & 69.0 \\
\hline \multicolumn{3}{|l|}{ Age (years) } \\
\hline$<25$ & 103 & 31.89 \\
\hline $25-40$ & 196 & 60.68 \\
\hline$>40$ & 24 & 7.43 \\
\hline \multicolumn{3}{|l|}{ Home address } \\
\hline Township or village & 208 & 64.4 \\
\hline County or county city & 87 & 26.9 \\
\hline City or district level city & 28 & 8.7 \\
\hline \multicolumn{3}{|l|}{ Number of children } \\
\hline 1 & 126 & 39 \\
\hline 2 & 137 & 42.4 \\
\hline 3 & 21 & 6.5 \\
\hline$>3$ & 39 & 12.1 \\
\hline \multicolumn{3}{|l|}{ Working conditions } \\
\hline Employed & 198 & 61.3 \\
\hline Unemployed & 106 & 32.8 \\
\hline Requested leave & 12 & 3.7 \\
\hline Retired & 7 & 2.2 \\
\hline \multicolumn{3}{|l|}{ Educational level } \\
\hline Primary school and below & 24 & 7.4 \\
\hline Junior middle school & 121 & 37.5 \\
\hline $\begin{array}{l}\text { High school or technical } \\
\text { secondary school }\end{array}$ & 123 & 38.1 \\
\hline College or above & 55 & 17 \\
\hline \multicolumn{3}{|l|}{ Family monthly income } \\
\hline Less than 1,000 yuan & 51 & 15.8 \\
\hline $1,000-3,000$ yuan & 88 & 27.2 \\
\hline $3,000-5,000$ yuan & 129 & 39.9 \\
\hline $5,000-10,000$ yuan & 55 & 17 \\
\hline$>10,000$ yuan & 0 & 0 \\
\hline
\end{tabular}

$\mathrm{IH}$, infantile hemangioma.
Table 3 General information and disease information of the IHs $(\mathrm{n}=323)$

\begin{tabular}{|c|c|c|}
\hline Characteristic & Number & Proportion (\%) \\
\hline \multicolumn{3}{|l|}{ Gender } \\
\hline Male & 89 & 27.6 \\
\hline Female & 234 & 72.4 \\
\hline \multicolumn{3}{|l|}{ Lesion } \\
\hline Head and neck surface & 192 & 59.4 \\
\hline Trunk & 54 & 16.7 \\
\hline Limbs & 60 & 18.6 \\
\hline Perineum & 17 & 5.3 \\
\hline \multicolumn{3}{|l|}{ Duration of illness (months) } \\
\hline$<2$ & 133 & 41.2 \\
\hline $2-4$ & 62 & 19.2 \\
\hline $4-6$ & 48 & 14.9 \\
\hline$>6$ & 80 & 24.8 \\
\hline \multicolumn{3}{|l|}{ Main caregiver } \\
\hline Parent & 80 & 24.8 \\
\hline Nanny & 38 & 11.8 \\
\hline Grandparent & 181 & 56 \\
\hline Others & 24 & 7.4 \\
\hline \multicolumn{3}{|c|}{ Whether to receive treatment } \\
\hline Treated & 215 & 66.6 \\
\hline Untreated & 108 & 33.3 \\
\hline \multicolumn{3}{|l|}{ Single/multiple occurrence } \\
\hline Single & 271 & 83.9 \\
\hline Multiple & 52 & 16.1 \\
\hline \multicolumn{3}{|l|}{ Tumor size $\left(\mathrm{cm}^{2}\right)$} \\
\hline$<1$ & 28 & 8.7 \\
\hline $1-10$ & 208 & 64.4 \\
\hline$>10$ & 87 & 26.9 \\
\hline \multicolumn{3}{|l|}{ Focal depth } \\
\hline Superficial & 250 & 77.4 \\
\hline Deep type & 30 & 9.3 \\
\hline Mixture & 43 & 13.3 \\
\hline \multicolumn{3}{|c|}{ Presence/absence of complications } \\
\hline Presence & 69 & 21.4 \\
\hline Absence & 254 & 78.6 \\
\hline
\end{tabular}


Table 4 Item analysis of the questionnaire

\begin{tabular}{|c|c|c|c|c|c|c|c|c|}
\hline \multirow{2}{*}{$\begin{array}{l}\text { Item } \\
\text { number }\end{array}$} & \multirow{2}{*}{$\begin{array}{c}\begin{array}{c}\text { Extreme value } \\
\text { comparison }\end{array} \\
\text { Critical ratio }\end{array}$} & \multicolumn{2}{|c|}{$\begin{array}{c}\text { Correlation between entry and } \\
\text { total score }\end{array}$} & \multicolumn{3}{|c|}{ Homogeneity test } & \multirow{2}{*}{$\begin{array}{c}\text { Number of } \\
\text { - unqualified } \\
\text { indicators }\end{array}$} & \multirow{2}{*}{ Remarks } \\
\hline & & $\begin{array}{l}\text { Correlation } \\
\text { coefficient }\end{array}$ & $\begin{array}{c}\text { Corrected correlation } \\
\text { coefficient }\end{array}$ & $\begin{array}{l}\text { The alpha value of } \\
\text { item deletion }\end{array}$ & Commonality & Factor loading & & \\
\hline 1 & 3.651 & 0.356 & 0.310 & 0.950 & 0.113 & 0.336 & 5 & Delete \\
\hline 2 & 5.124 & 0.582 & 0.547 & 0.948 & 0.388 & 0.623 & 0 & Retain \\
\hline 4 & 13.877 & 0.412 & 0.362 & 0.950 & 0.102 & 0.320 & 4 & Delete \\
\hline 5 & 14.946 & 0.551 & 0.518 & 0.948 & 0.296 & 0.544 & 0 & Retain \\
\hline 6 & 17.625 & 0.649 & 0.619 & 0.947 & 0.411 & 0.641 & 0 & Retain \\
\hline 7 & 12.125 & 0.725 & 0.696 & 0.946 & 0.540 & 0.735 & 0 & Retain \\
\hline 11 & 4.968 & 0.336 & 0.303 & 0.949 & 0.098 & 0.313 & 4 & Delete \\
\hline 12 & 7.418 & 0.550 & 0.525 & 0.948 & 0.339 & 0.582 & 0 & Retain \\
\hline 13 & 3.952 & 0.660 & 0.638 & 0.947 & 0.488 & 0.698 & 0 & Retain \\
\hline 14 & 7.528 & 0.812 & 0.796 & 0.946 & 0.667 & 0.817 & 0 & Retain \\
\hline 15 & 14.914 & 0.803 & 0.781 & 0.946 & 0.618 & 0.786 & 0 & Retain \\
\hline 16 & 9.186 & 0.761 & 0.741 & 0.946 & 0.608 & 0.780 & 0 & Retain \\
\hline 17 & 11.656 & 0.788 & 0.765 & 0.946 & 0.609 & 0.780 & 0 & Retain \\
\hline 24 & 25.633 & 0.760 & 0.727 & 0.946 & 0.496 & 0.705 & 0 & Retain \\
\hline 25 & 8.602 & 0.542 & 0.508 & 0.948 & 0.256 & 0.506 & 0 & Retain \\
\hline 26 & 8.999 & 0.269 & 0.232 & 0.950 & 0.040 & 0.199 & 5 & Delete \\
\hline 27 & 4.968 & 0.808 & 0.797 & 0.947 & 0.766 & 0.875 & 0 & Retain \\
\hline 28 & 3.723 & 0.719 & 0.703 & 0.947 & 0.626 & 0.791 & 0 & Retain \\
\hline 29 & 12.341 & 0.357 & 0.297 & 0.951 & 0.086 & 0.293 & 3 & Delete \\
\hline 30 & 5.620 & 0.808 & 0.795 & 0.946 & 0.751 & 0.866 & 0 & Retain \\
\hline 31 & 5.371 & 0.248 & 0.225 & 0.949 & 0.049 & 0.221 & 4 & Delete \\
\hline 32 & 7.336 & 0.693 & 0.671 & 0.947 & 0.498 & 0.705 & 0 & Retain \\
\hline 33 & 7.925 & 0.716 & 0.698 & 0.947 & 0.587 & 0.766 & 0 & Retain \\
\hline 34 & 23.108 & 0.752 & 0.731 & 0.946 & 0.542 & 0.736 & 0 & Retain \\
\hline 35 & 1.946 & 0.390 & 0.352 & 0.949 & 0.160 & 0.400 & 5 & Delete \\
\hline Standard & $\geq 3.000$ & $\geq 0.400$ & $\geq 0.400$ & $\leq 0.949$ & $\geq 0.200$ & $\geq 4.500$ & & \\
\hline
\end{tabular}


not meet the standard, leaving 27 items after their deletion.

\section{Validity evaluation}

Factor analysis was used to investigate the construct validity of the questionnaire. The software SPSS 18.0 (IBM Corp., Chicago, IL, USA) showed that Kaiser-Meyer-Olkin (KMO) value was 0.750 , and the $\chi^{2}$ value of Bartlett spherical test was $6,114.620(\mathrm{P}<0.05)$. There was a significant difference between the correlation coefficient matrix and the unit matrix, indicating that the questionnaire was suitable for factor analysis. The principal component analysis (PCA) method was used to select the orthogonal rotating shaft mode, and the factor with an eigenvalue of greater than 1 was selected.

The results of exploratory factor analysis found that 6 factors could be extracted with a cumulative contribution rate of $85.014 \%$. Factor 6, however, contained only 2 items (item $3 \& 12$ ), which did not meet the requirements. Deleted items 3 and 12 could be extracted after 5 factors, with a cumulative contribution rate of $83.239 \%$. All the entries on the corresponding load factor were above 0.4 . However, item 13 in the first factor and load on the fifth factor was above 0.4 at the same time, and item 7 in the second factor and the fourth factor load was higher than 0.4 at the same time. By the same method, the second factor analysis, in turn, deleted items 13 and 7. The results showed that the load of all items only on the corresponding factor was above 0.4 , which met the requirements of the questionnaire.

According to the contents, the first factor, which included 6 items, demonstrated the degree of depression of parents of children with IH. The second factor, which included 5 items, represented the anxiety level of the parents. The third factor, which included 4 items, represented the psychological balance of the parents. The fourth factor which included 5 items represented the parents' level of fear for the disease. The fifth factor, including 4 items, represented the degree of stigma of the parents due to the disease. These results (Table 5) demonstrated a wellstructured and more reasonable questionnaire that can better fit parents of children with IH.

Cronbach's $\alpha$ of SAS and SDS were 0.845 and 0.812 , respectively, and the correlation coefficients between SAS, SDS, and IH-PSQ were 0.874 and 0.754 , respectively $(\mathrm{P}<0.01)$, as shown in Table 6.

\section{Reliability analysis}

Cronbach's $\alpha$ of IH-PSQ was 0.957, while Cronbach's $\alpha$ of 5 factors were $0.941,0.914,0.915,0.849$, and 0.839 , respectively. The IH-PSQ split-half reliability was 0.971 , and the split-half reliabilities of 5 factors were $0.957,0.879$, $0.899,0.911$, and 0.865 , respectively (Table 7).

The correlation coefficient of test-retest reliability of IH-PSQ was 0.967 , and the correlation coefficient of testretest reliability of 5 factors was $0.987,0.947,0.977,0.967$, and 0.947 , respectively (Table 8).

A final, validated version of IH-PSQ is provided in Table 9.

\section{Analysis of influencing factors}

According to the survey of the 323 parents of children with $\mathrm{IH}$, the average score of IH-PSQ was $60.20 \pm 20.12$.

The results of multiple linear regression showed that education level of parents, duration of illness, tumor size, the presence or absence of complications, family monthly income, single or multiple occurrences, and whether to receive treatment entered the regression equation, indicating that these factors will affect the score of IH-PSQ, as shown in Table 10.

\section{Discussion}

The key reason that catalyzed this study was the unfortunate phenomena of overtreatment among some children with IH. Overtreatment of infants and young children exists in many countries (20). The reasons for this phenomenon included 2 aspects: doctor's reasoning, including the fear of accidents (12), lack of corresponding standards (20), and some moral factors (12); the other was parental psychological factors $(11,12)$. However, it was the guardians who ultimately decided the treatment of IH children. It was of positive significance to explore the psychological state of parents of children with $\mathrm{IH}$ in the pursuit of better service of children with IH (18).

The tools of investigation were important in this study. At the beginning, some researchers used the quality-of-life questionnaire to assess IH families (16), and emphasized the necessity for a specific questionnaire $(16,18)$. Next, 2 specialized questionnaires appeared: 1 was the IH-QoL (Infantile Hemangioma Quality-of-Life), which was verified by 220 respondents, containing 29 items, investigating the physical condition and social interaction of children with $\mathrm{IH}$ and the emotional and psychological functions of the parents of children with IH (21); The other was the Hemangioma Family Burden (HFB), which was verified by 75 respondents, containing 20 items, investigating family life, relationship and work, emotion/feeling, psychology, 
Table 5 Exploratory factor analysis of the questionnaire

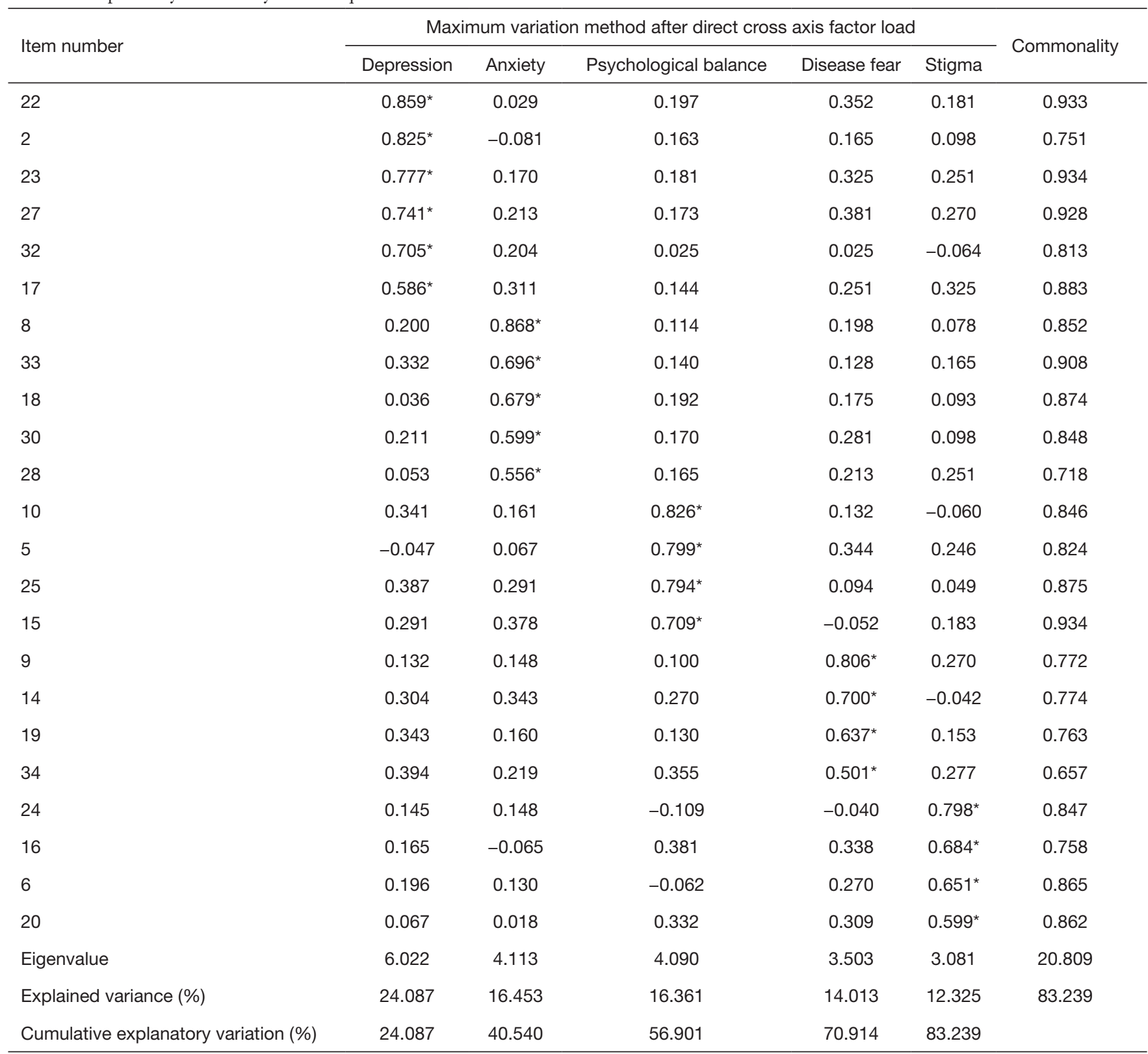

${ }^{*}$, the numbers are greater than 0.4 and can be included in the entry for the current dimension.

and disease management of the IH family (22). Their research had a positive effect on the better service of $\mathrm{IH}$ families. Researchers from another region of China used the IH-QoL to investigate local IH families and got similar results (23). However, we had noticed that the questionnaire mentioned had some regional limitations. We needed to go through a series of processes such as translation and re verification prior to its application. In addition, we required a questionnaire focusing on the psychological status of parents of children with $\mathrm{IH}$, because it has a great impact on the direction of treatment. However, the two above mentioned questionnaires seemed to focus more on the whole IH family. Based on this, we finally decided to develop a regional questionnaire that met our requirements. We would like others to use it in other areas, subject to reverification. 
Table 6 Criterion-related validity of the questionnaire

\begin{tabular}{lcc}
\hline \multirow{2}{*}{ Characteristic } & \multicolumn{2}{c}{ Score of IH-PSQ } \\
\cline { 2 - 3 } & $\begin{array}{c}\text { Score of the Self- } \\
\text { rating Scale }\end{array}$ & $\begin{array}{c}\text { Score of Self-rating } \\
\text { Depression Scale }\end{array}$ \\
\hline Pearson correlation & 0.874 & 0.754 \\
Significance (bilateral) & $<0.01$ & $<0.01$ \\
$\mathrm{n}$ & 50 & 50 \\
\hline
\end{tabular}

IH-PSQ, Psychologic Status Questionnaire for parents of Infantile Hemangiomas.

Table 7 Internal consistency reliability and split half reliability of the questionnaire

\begin{tabular}{lccc}
\hline Dimensions of IH-PSQ & $\begin{array}{c}\text { Number of } \\
\text { items }\end{array}$ & $\begin{array}{c}\text { Cronbach's } \\
\text { alpha }\end{array}$ & $\begin{array}{c}\text { Split half } \\
\text { reliability }\end{array}$ \\
\hline Depression & 6 & 0.941 & 0.957 \\
Anxiety & 5 & 0.912 & 0.879 \\
Psychological imbalance & 4 & 0.915 & 0.899 \\
Disease fear & 4 & 0.849 & 0.911 \\
Stigma & 4 & 0.839 & 0.865 \\
The questionnaire & 23 & 0.957 & 0.971
\end{tabular}

IH-PSQ, Psychologic Status Questionnaire for parents of Infantile Hemangiomas.

Table 8 Test-retest reliability of each factor and whole questionnaire

\begin{tabular}{lcc}
\hline Dimensions of IH-PSQ & $\begin{array}{c}\text { Number of } \\
\text { items }\end{array}$ & $\begin{array}{c}\text { Correlation } \\
\text { coefficient }\end{array}$ \\
\hline Depression & 6 & 0.987 \\
Anxiety & 5 & 0.947 \\
Psychological balance & 4 & 0.977 \\
Disease fear & 4 & 0.967 \\
Stigma & 4 & 0.947 \\
Whole & 23 & 0.967 \\
\hline
\end{tabular}

IH-PSQ, Psychologic Status Questionnaire for parents of Infantile Hemangiomas.

It was difficult to name this questionnaire. There was no other single questionnaire that involved all the dimensions mentioned in this questionnaire, namely anxiety, depression, psychological imbalance, stigma and fear of the disease, and the survey participants were parents of children with IH. These dimensions actually involved the emotional, psychological, and mental state of parents. After several rounds of team discussions, we finally chose the name of the Psychologic Status Questionnaire for Infantile Hemangiomas' parents (IHPSQ) because it was more inclusive.

As the location of the survey was the outpatient department of the hospital, the information we gathered was more comprehensive. The possible influencing factors of our questionnaire were more than those of the studies we had previously seen, but it was still not a comprehensive overview. The study showed that there were two aspects affecting the score of the questionnaire: parent-driven factors were monthly income and education level. That means that parents with lower education levels and lower family income are more likely to be affected by psychological conditions such as anxiety and depression; disease-related factors were time of illness, tumor size, presence or absence of complications, single or multiple hemangiomas, and whether they had already been treated. That means the longer the illness, the larger the tumor, the more tumors, complications, and no treatment can make the parents more susceptible to depression, anxiety and other psychological states. Clinicians should focus on those factors in order to better communicate with the parents of children with IH. Some of these factors have been previously mentioned, such as the educational level of parents (23) and the size of the tumor $(22,23)$. Some of the reasons that were not mentioned may be related to the different survey tools and the number of survey-related factors. In addition, what we need to know is that the psychological adjustment ability and positive attitude of parents have a very positive significance to relieve stress and the quality of family life (21). This should be advocated clinically and will help many IH families.

There are two main limitations to the study. The sampling was mainly from the patients of the Clinical Research Center of Vascular Abnormalities in Jiangxi Province, China, which was convenient but had systematic errors. We should enlarge the sample size and include different regions and hospitals so as to reduce the systematic error and selection deviation. Also, our goal of reducing IH overtreatment was only the first step, and we did not identify a link between questionnaire scores and overtreatment. The link will become clearer with the increase of the clinical application of the questionnaire, and we will finally achieve the purpose of reducing overtreatment. What we know is that the parents' psychological distress will be better because of the treatment. When we introduced the treatment of IH to the parents in detail, it was obvious that 
Table 9 Final validated version of IH-PSQ

Instructions: here are some questions about your recent psychological status. Please read each question carefully, and then score from 0 to 5 for every item $(0=$ never/not applicable, $1=$ rarely, $2=$ sometimes, $3=$ often, $4=$ very often, $5=$ constantly)

1. After my child got IH, I was more likely to feel tired (Depression)

2. After my child got $\mathrm{IH}$, I was worried that the treatment would affect their growth and development (Stigma)

3. After my child got $\mathrm{IH}, \mathrm{I}$ felt the $\mathrm{IH}$ of other children recovered better than mine (Psychological balance)

4. After my child got IH, I would think of my own child and feel uncomfortable when I saw other people's children were healthy (Psychological balance)

5. After my child got IH, I felt that my children needed more love than other children (Stigma)

6. After my child got IH, I worried that the children born to me would also suffer from this disease in the future (Fear)

7. After my child got $\mathrm{IH}$, I was depressed and not in a high mood (Depression)

8. After my child got IH, I was afraid to expose the affected areas (Fear)

9. After my child got IH, I attributed the cause of illness to myself (Psychological balance)

10. After my child got IH, I felt nervous every time the doctor made an appointment or regular check-up (Fear)

11. After my child got IH, I was upset about many things (Anxiety)

12. After my child got IH, I thought everyone made mistakes (Anxiety)

13. After my child got IH, life was not as comfortable as before (Stigma)

14. After my child got IH, It was difficult for me to calm down and think (Anxiety)

15.After my child got IH, my living and working conditions were not good (Depression)

16. After my child got $\mathrm{IH}$, I was prone to nightmares (Depression)

17.After my child got IH, my digestion became worse (Anxiety)

18.After my child got IH, I slept worse than before (Anxiety)

19.After my child got IH, I felt that this family was not good enough for my child (Stigma)

20.After my child got IH, I sought medical advice everywhere (Fear)

21.After my child got IH, I felt God was unfair to me and my child (Psychological balance)

22.After my child got $\mathrm{IH}$, I did not want entertainment (Depression)

23.After my child got IH, I quarreled with the people around me more than before (Depression)

Tips: in practice, it is not necessary to show the brackets after the items. IH-PSQ, Psychologic Status Questionnaire for parents of Infantile Hemangiomas; $\mathrm{IH}$, infantile hemangioma.

Table 10 Multiple linear regression analysis of the influence factors of IH-PSQ

\begin{tabular}{lccccc}
\hline Factors & $\beta$ value & Standard error & $\begin{array}{c}\text { Standard regression } \\
\text { coefficient } \beta\end{array}$ & t value & $\begin{array}{c}\text { Coefficient of } \\
\text { determination } R^{2}\end{array}$ \\
\hline Constant term & 44.211 & 3.537 & & 12.500 & $<0.01$ \\
Education level & 10.276 & 2.659 & 0.225 & 3.865 & $<0.01$ \\
Duration of illness & 20.590 & 3.687 & 0.372 & 5.584 & $<0.01$ \\
Tumor size & -7.038 & 2.631 & -0.146 & -2.675 & 0.008 \\
Complications & -6.228 & 2.451 & -0.141 & -2.540 & 0.012 \\
Family monthly income & -5.979 & 2.405 & -0.140 & -2.486 & 0.014 \\
Single or multiple occurrences & 6.128 & 3.000 & 0.122 & 2.043 & 0.042 \\
Whether to receive treatment & 9.087 & 4.531 & 0.111 & 2.005 & 0.046 \\
\hline
\end{tabular}

IH-PSQ, Psychologic Status Questionnaire for parents of Infantile Hemangiomas. 
their psychological state was better, which fully indicated that the change of cognition of the disease could help the parents to relieve their psychological distress.

The verification process of the questionnaire involved 323 families with IH. A questionnaire with 5 dimensions was produced through a series of processes such as item analysis, validity analysis, and reliability analysis. The structure and reliability of the questionnaire was supported by strong evidence. The objective assessment of the psychological status of parents of children with IH will enhance communication between the parents and health care providers, thereby improving information transfer, creating a real opportunity for practitioners to gain better understanding of certain issues brought up by the patients or their families, and avoid overtreatment. Moreover, IHPSQ may help parents of children with IH to understand their psychological status and seek help from psychiatrists to harmonize their daily life.

\section{Conclusions}

The IH-PSQ demonstrated its reliability and validity, and can therefore be used to better understand the multidimensional nature of the psychological status of parents of children with IH, including anxiety, depression, psychological imbalance, sense of shame, and disease fear. Using the verified IH-PSQ, we provided further insight into the psychological status of local parents of children with IH and highlighted potential factors for future focus in assisting families with affected children, which include parents' own factors (including monthly income and education level) and disease-related factors (including duration of illness, tumor size, the presence or absence of complications, single or multiple occurrences, and whether treatment should be implemented).

\section{Acknowledgments}

The investigators would like to acknowledge the junior fellow apprentice who participated in the co-design process. Thanks are extended for the platform provided by the First Affiliated Hospital of Gannan Medical University and Jiangxi Provincial Clinical Medical Research Center for Vascular Abnormalities, and for the technical support provided by Gannan Medical University.

Funding: This project was supported by the Key Project of Natural Science Foundation of Jiangxi Province (No. 20192ACBL20005) and the Youth Project of Jiangxi
Provincial Department of Education (No. GJJ201550). In addition, this study was supported by the Jiangxi Provincial Clinical Research Center for Vascular Anomalies and Jiangxi Provincial Key Laboratory of Traditional Chinese Medicine Prevention and Treatment of Hemangioma.

\section{Footnote}

Reporting Checklist: The authors have completed the MDAR reporting checklist. Available at https://dx.doi. org/10.21037/tp-21-554

Data Sharing Statement: Available at https://dx.doi. org/10.21037/tp-21-554

Conflicts of Interest: All authors have completed the ICMJE uniform disclosure form (available at https://dx.doi. org/10.21037/tp-21-554). The authors have no conflicts of interest to declare.

Ethical Statement: The authors are accountable for all aspects of the work in ensuring that questions related to the accuracy or integrity of any part of the work are appropriately investigated and resolved. All procedures performed in this study involving human participants were approved by the Ethics Committee of The First Affiliated Hospital of Gannan Medical University (No. LLSC2021062503) and were in accordance with the Declaration of Helsinki (as revised in 2013). All participants voluntarily participated in the study and signed a written informed consent before taking part.

Open Access Statement: This is an Open Access article distributed in accordance with the Creative Commons Attribution-NonCommercial-NoDerivs 4.0 International License (CC BY-NC-ND 4.0), which permits the noncommercial replication and distribution of the article with the strict proviso that no changes or edits are made and the original work is properly cited (including links to both the formal publication through the relevant DOI and the license). See: https://creativecommons.org/licenses/by-nc-nd/4.0/.

\section{References}

1. Kilcline C, Frieden IJ. Infantile hemangiomas: how common are they? A systematic review of the medical literature. Pediatr Dermatol 2008;25:168-73.

2. Chang LC, Haggstrom AN, Drolet BA, et al. Growth 
characteristics of infantile hemangiomas: implications for management. Pediatrics 2008;122:360-7.

3. Chen ZY, Wang QN, Zhu YH, et al. Progress in the treatment of infantile hemangioma. Ann Transl Med 2019;7:692.

4. Léauté-Labrèze C, Prey S, Ezzedine K. Infantile haemangioma: part I. Pathophysiology, epidemiology, clinical features, life cycle and associated structural abnormalities. J Eur Acad Dermatol Venereol 2011;25:1245-53.

5. Editorial Team of Pediatric Investigation; Zhang J. Professor Jinzhe Zhang: An accomplished and upright doctor who emphasizes benevolence and humanistic care of sick children. Pediatr Investig 2018;2:1-3.

6. Zhang J. Challenges faced by pediatric oncology work at present. International Symposium on Pediatric Oncology and National Academic Conference on Pediatric Oncology 2003:1-4.

7. Zheng JW, Wang XK, Qin ZP, et al. Chinese experts consensus on the use of oral propranolol for treatment of infantile hemangiomas. Shanghai Kou Qiang Yi Xue 2016;25:257-60.

8. Dyer JA. Propranolol to Treat Hemangiomas of Infancy: Safety and Side Effect Recognition: Comment on "Retrospective Review of Adverse Effects from Propranolol in Infants". JAMA Dermatol 2013;149:481-504.

9. Welsh O, Welsh EC, Cárdenas JA. Aesthetic/cosmetic cryosurgery//Dermatological Cryosurgery and Cryotherapy. London: Springer, 2016:269-76.

10. Hadler NM. Medical Overtreatment: Friend or Foe? Gerontology 2018;64:222-8.

11. Pausch M, Schedlbauer A, Weiss M, et al. Is it really always only the others who are to blame? GP's view on medical overuse. A questionnaire study. PLoS One 2020;15:e0227457.

12. Lyu H, Xu T, Brotman D, et al. Overtreatment in the United States. PLoS One 2017;12:e0181970.

Cite this article as: Peng W, Liu H, Chen J, Zheng Y, Xu X, Tang H, Liu Q. Development and validation of psychological status questionnaire for parents of infantile hemangiomas. Transl Pediatr 2021;10(12):3261-3272. doi: 10.21037/tp-21-554
13. Haggstrom AN, Drolet BA, Baselga E, et al. Prospective study of infantile hemangiomas: clinical characteristics predicting complications and treatment. Pediatrics 2006;118:882-7.

14. Léauté-Labrèze C, Prey S, Ezzedine K. Infantile haemangioma: part II. Risks, complications and treatment. J Eur Acad Dermatol Venereol 2011;25:1254-60.

15. Dieterich-Miller CA, Safford PL. Psychosocial development of children with hemangiomas: home, school, health care collaboration. Child Health Care 1992;21:84-9.

16. Hoornweg MJ, Grootenhuis MA, van der Horst CM. Health-related quality of life and impact of haemangiomas on children and their parents. J Plast Reconstr Aesthet Surg 2009;62:1265-71.

17. Tanner JL, Dechert MP, Frieden IJ. Growing up with a facial hemangioma: parent and child coping and adaptation. Pediatrics 1998;101:446-52.

18. Zweegers J, van der Vleuten CJ. The psychosocial impact of an infantile haemangioma on children and their parents. Arch Dis Child 2012;97:922-6.

19. Wu M. Practice of questionnaire statistical analysis: SPSS operation and application. Chongqing: Chongqing University Press, 2010.

20. Frey B. Overtreatment in threshold and developed countries. Arch Dis Child 2008;93:260-3.

21. Chamlin SL, Mancini AJ, Lai JS, et al. Development and Validation of a Quality-of-Life Instrument for Infantile Hemangiomas. J Invest Dermatol 2015;135:1533-9.

22. Boccara O, Méni C, Léauté-Labreze C, et al. Haemangioma family burden: creation of a specific questionnaire. Acta Derm Venereol 2015;95:78-82.

23. Wang C, Li Y, Xiang B, et al. Quality of life in children with infantile hemangioma: a case control study. Health Qual Life Outcomes 2017;15:221.

(English Language Editor: J. Jones) 